\title{
André Gide, Gide \& Amrouche. Correspondance (1928-1950)
}

\section{Veronica Amadessi}

\section{Q OpenEdition}

1 Journals

\section{Édition électronique}

URL : https://journals.openedition.org/studifrancesi/3241

DOI : 10.4000/studifrancesi.3241

ISSN : 2421-5856

Éditeur

Rosenberg \& Sellier

\section{Édition imprimée}

Date de publication : 1 juillet 2013

Pagination : 496

ISSN : 0039-2944

\section{Référence électronique}

Veronica Amadessi, «André Gide, Gide \& Amrouche. Correspondance (1928-1950)», Studi Francesi [En ligne], 170 (LVII | II) | 2013, mis en ligne le 30 novembre 2015, consulté le 02 février 2023. URL : http:// journals.openedition.org/studifrancesi/3241 ; DOI : https://doi.org/10.4000/studifrancesi.3241

Ce document a été généré automatiquement le 2 février 2023.

\section{(c) $(1) \&$}

Creative Commons - Attribution - Pas d'Utilisation Commerciale - Pas de Modification 4.0 International - CC BY-NC-ND 4.0

https://creativecommons.org/licenses/by-nc-nd/4.0/ 


\title{
André Gide, Gide \& Amrouche. Correspondance (1928-1950)
}

\author{
Veronica Amadessi
}

\section{RÉFÉRENCE}

ANDRÉ GIDE, Gide \& Amrouche. Correspondance (1928-1950), éd. établie par Pierre MASSON et Guy DUGAS, Lyon, PUL, 2010, pp. 351.

1 En 1928, le jeune Jean el-Mouhoub Amrouche captive l'attention d'André Gide dans une lettre qu'il lui adresse personnellement. À cette époque, la réputation de l'auteur de L'Immoraliste ne cesse de grandir, alors que l'expéditeur n'est qu'un «brillant» normalien inconnu au grand public. Il s'agit toutefois d'un jeune kabyle aux idées bien précises, qui exprime, dans cette première missive, sa volonté de se faire le porteparole de l'identité kabyle tout en préservant son amour pour la France. Ce «fils africain de la France», comme il aime se définir, touche Gide, qui à son tour, fasciné par l'Afrique, rêve de donner une voix aux peuples colonisés et opprimés.

2 C'est ainsi que se met en place, en deux temps distincts, cette correspondance, qui couvre une vingtaine d'années. En effet, une première partie de ces échanges a lieu entre 1928 et 1933, lorsque le jeune Amrouche, parfois perdu face à l'avenir qui l'attend, espère pouvoir concilier sa double identité française et kabyle, l'une ayant besoin de l'autre pour se révéler. Gide, quant à lui, représente dans ces années-là une sorte de guide spirituel pour son jeune correspondant: Amrouche s'adresse à lui en l'appelant «Maître» et en montrant une admiration qui touche souvent à l'idéalisme.

3 La vie et ses contraintes éloignent les deux hommes pendant quelques années. Mais en 1939 paraissent les Chants berbères de Kabylie, publication qui permet à Amrouche d'assumer ce rôle de "passeur» entre deux cultures dont il rêvait depuis des années. La correspondance entre les deux auteurs reprend et s'inscrit maintenant dans le cadre d'une amitié durable, renforcée par le séjour de Gide en Tunisie à partir de 1942 où ce dernier lance une revue, «L'Arche», à laquelle Amrouche participe activement. Dans les 
lettres échangées au cours de cette période s'entremêlent à la fois l'aventure éditoriale de la revue et le désir pressant, de la part d'Amrouche, de faire une œuvre qui ne verra jamais le jour. Les lettres du jeune professeur témoignent de cette angoisse liée au renvoi permanent du passage à l'écriture. La correspondance s'arrête en 1950, peu avant la mort du «Maître».

4 Pierre MASSON et Guy DUGAS, qui ont établi, présenté et annoté cette édition, apportent, grâce à ce recueil, une importante contribution aux études gidiennes. L'ouvrage est enrichi d'annexes contenant des articles et des textes publiés dans les journaux et les revues de l'époque. Parmi ces derniers, si certains ont un intérêt anecdotique, comme quelques brouillons de lettres, d'autres éclairent les propos des deux correspondants et leur activité littéraire et éditoriale, comme par exemple le Manifeste de «L'Arche». Tout l'ensemble, lettres et textes annexes, tracent une volonté, chez Amrouche, de concilier deux cultures et deux mondes et soulignent chez Gide l'idée d'une culture universelle au-delà des conflits qui ont ravagé l'Europe. 